\title{
Implementation of Van Hiele Learning Model Assisted By Manipulative Media in Circle Materials to Improve the Learning Outcomes of Violent Students Inpres Palupi Elementary School
}

\author{
Prasetyowati, Pathuddin, Sutji Rochaminah, Rahmat Hidayatullah \\ Mathematics Education Masters Program - Tadulako University
}

\begin{abstract}
The purpose of this study was to obtain a description of student learning outcomes through the Van Hiele learning application model assisted by manipulative media on the circle material of Grade VI students of SD Inpres Palupi. This type of research is classroom action research which refers to the PTK model developed by Arikunto.S which consists of four components in each cycle, namely (1) planning, (2) implementing the action, (3) observation and (4) reflection. The research subjects were grade VI students of SD Inpres Palupi Palu, totaling 26 students consisting of 12 male students and 14 female students. Data collected in this study through observation sheets, interviews, field notes, and student learning outcomes data. In the final test cycle I, there were 12 students who have completed and 14 students did not complete so that the percentage of classical completeness of students in the first cycle $I$ is $46.15 \%$. Whereas in cycle II there were 22 students complete and 4 students not completing so that the percentage of classical completeness of students in cycle II was $84.62 \%$. The results showed that the activities of teachers and student activities in learning have increased and indicators of success in the action have been achieved. Based on these results, it can be concluded that the application of the Van Hiele learning model assisted by manipulative media can improve learning outcomes of Grade VI students at SD Inpres Palupi on circle material through the following phases: 1) information phase, 2) direct orientation phase, 3) explanation phase , 4) orientation-free phase and 5) integration phase
\end{abstract}

Keywords: Van Hiele Learning Model, Learning Outcomes, Circles.

\section{INTRODUCTION}

$\mathrm{M}$ athematics is one of the sciences that underlies the development of science, technology and art and has always played an important role in various scientific disciplines. Therefore, mathematics learning needs to be given to all students from preschool to high school, even to college. Through mathematics students will have the ability to think logically, analyze, systematically, critically and creatively and work together(Depdiknas, 2006).

The purpose of learning mathematics in elementary schools in general in the 2013 Curriculum is to understand factual, conceptual, procedural, and metacognitive knowledge at the basic level by observing, questioning, and trying based on curiosity about himself, God's creatures and their activities, and objects. which he finds at home, at school, and in the playground (Ministry of Education and Culture, 2016).

Basic Competencies learned in elementary school, especially in grade VI include Fractions, Scale and Comparison, Geometry and Statistics. Knowing a circle and calculating the area and circumference of a circle are competencies in geometry. Basically, geometry is familiar to students compared to other branches of mathematics. This is because the ideas of geometry have been known by students sincebefore they enter school, for example lines, fields, and spaces (Sholiha \& Afriansyah, 2017). Students get to know geometry through objects that contain geometric shapes and concepts or geometric models in their environment, for example: football field shapes, door shapes, window shapes, house shapes, floor tiles, book shapes, and so on.(Abdussakir, 2012).

Based on the experience of researchers teaching in grade VI SD Inpres Palupi, there are some materials that are difficult to teach in mathematics, including circles and integer arithmetic operations. The difficulty of teaching this material is because most students do not have a good foundation, so that when students are given a problem to solve they are very difficult to connect the material that has been studied with the material to be studied. The difficulty in connecting because the material that has been previously studied is not well understood. Teachers usually teach according to the curriculum so they have to move the material as planned. As a result of not understanding the previous material, students are also passive in learning, not excited and even not motivated because the basis for learning the material at hand is not owned.

During the lesson, students listen to the teacher's explanation but only a few students dare to ask questions. Many of the students said they understood the material described, but when the daily tests were held, the results were not as expected. Most of the students scored below the minimum passing standards. Mathematics learning outcomes, especially circle material are still low. The results of semester 1 of the 2019/2020 academic year show that the average student grade is 64 while the standard KKM for grade VI mathematics is 70 . namely in learning to build tubes and cones. 
Based on these problems, the researcher will conduct research to improve the learning process by applying Van Hiele learning. The application of Van Hiele learning will make the learning process more memorable for students, through the learning phases of the Van Hiele model.

Van Hiele's learning aplication model consists of five learning phases that can guide students in constructing geometric concepts. These phases include: information phase, orientation phase, explanation phase, free orientation phase and integration phase(Maghrib, 2018). In Van Hiele's learning, in the information phase a teacher ensures students' abilities in geometric form. Furthermore, in the direct orientation phase, abstract geometric shapes are concretized with learning media. Students manipulate the learning media so that a concept is created and the teacher ensures its correctness (explanation). Furthermore, doing exercises to generate concept understanding (free orientation). In the end, students are looking back towards the learning material (integration). This phase has been made in a structured manner and involves all spatial abilities(Husnul, 2013).

Van Hiele's model proposes a geometric thinking learning phase that helps students move from one level to a higher level of thinking. The learning process consists of five phases: (1) information; (2) guided orientation; (3) explanation; (4) free orientation; (5) integration(Abdullah, Surif, Ibrahim, \& Zakaria, 2015). Based on the research, the Van Hiele theorybased learning model can improve students' understanding of the properties of cubes, beams, prisms and pyramids.(Turella \& Dyiah, 2016).

Another factor that affects student learning outcomes is the use of media in learning. In order for the learning objectives to be achieved and the creation of a learning process that is not boring, teachers can use learning media appropriately. The use of media in learning is to be able bridge abstract mathematical concepts to be more concrete, so that students can understand the material presented by the teacher. For this reason, the use of media in the learning process is very necessary in order to achieve optimal learning objectives.Widyantini and Guntoro (Muzdalivah, Tandiayuk, \& Anggraini, 2016) states that the function of mathematics teaching aids, which makes it easier to understand a concept in mathematics and motivates or to arouse student interest in a concept. The result of research on mathematics learning by utilizing manipulative objects can improve students' understanding of the concept of geometry and the ability of spatial insight (Mukhlesi, 2011).The use of media in mathematics learning in SD is very necessary, because it is in accordance with the child's thinking stage. By using the right media / teaching aids, the child will appreciate mathematics in a real way based on clear and visible facts so that students can more easily understand the material being taught.

\section{RESEARCH METHODS}

Types of researchThis is a classroom action research which refers to the design of the research model developed by
Arikunto $\mathrm{S}$ which consists of four components, namely planning, implementing actions, observing and reflecting. The subjects of this classroom action research were students and teachers of class VI / A SD Inpres Palupi, Tatanga District, Palu City, Academic Year 2020/2021, with 26 students.

Data collection techniques in this study were carried out by qualitative data collection techniques through observation, interviews and field notes and quantitative data collection techniques through written tests on the pre-test and post-test actions in cycle I and cycle II. The data is analyzed using a flow model that refers to the Miles and Huberman model, namely: (1) reducing data, (2) presenting data, and (3) drawing conclusions / verification(Miles \& Huberman, 1992).

The success of the action in this study can be seen from the results of the final action test, the percentage of classical completeness and the activities carried out by the teacher in managing learning and the activities of students participating in learning by applying the Van Hiele learning model assisted by manipulative media. Teacher and student activities in the learning process are declared successful if every aspect assessed is in the good and very good categories. A student is said to be complete if the final test result reaches a value of more than or equal to 70 . The success of the action is also seen from classical completeness if it reaches $75 \%$ or more.

\section{RESEARCH RESULT}

This research consists of two stages, namely the pre-research and the implementation stage of the action. The activities carried out in the pre-research stage were identifying problems in the class, determining research subjects, and carrying out preliminary tests as guidelines for determining informants and forming study groups. The number of students who took the initial test was 26 students. The results of the preliminary test analysis showed that of the 26 students, 8 students were able to correctly solve the given questions, while the other 18 students still had difficulty solving the questions given. Based on the results of the preliminary test, the researcher determined 3 informants, namely $\mathrm{FH}$ (high ability), AN (low ability), and AR (low ability).

The implementation of this action consists of two cycles. Cycle I was carried out in two meetings with material elements of the circle and the circumference of the circle. Cycle II is held once a meeting with circle area material. Each cycle refers to the model developed by Arikunto, which is that each cycle consists of (1) planning, (2) implementing actions, (3) observation and (4) reflection. The observation stage is carried out together when the action takes place.

Process The implementation of learning cycle I and cycle II is carried out in accordance with the learning implementation plan which consists of preliminary, core and closing activities. These activities correspond to the phases of the Van Hiele learning model. The phases in learning consist of five phases, namely the information phase, the direct orientation phase, the 
explanation phase, the free orientation phase and the integration phase.

\section{1) Preliminary activities}

Implementation of the first cycle of action, the preliminary stage begins by doing the opening namely give the opening greeting and pray to begin the study. The next activity is checking student attendance and preparing physically and psychologically, especially according to health protocols in starting learning activities. Students who attended that day were 24 of the total 26 students of class VI A. There were 2 students who were absent due to illness. The results obtained are that the teacher can find out which students are not present that day and students can prepare themselves to take part in the lesson well even though the atmosphere at that time was still a little rowdy. Furthermore, the researcher provides an overview of the benefits of studying circular material in everyday life and the researcher conveys the learning objectives to be achieved. The Learning objectivesin cycle I, namely: students can determine the elements of a circle, students can explain several terms related to the elements of a circle, students can explain the circumference of a circle, students can calculate the circumference of a circle. While the learning objectives in cycle II, namely: students can explain the area of a circle and students can calculate the area of a circle. Furthermore, the researcher explains the mechanism for implementing the learning experience according to the learning steps. The results achieved by students know the steps to be taken in learning.

\section{Information Phase}

Researchers provide apperception to students by asking and answering questions about the circle material that has been studied previously. In the information phase of the first cycle of the first meeting, the researcher asked about circular objects in everyday life and asked about the elements of the circle, most students did not understand the elements of the circle. Furthermore, the researcher first introduced the elements of the circle in outline before the students carried out the activities contained in the activity instruction sheet. The second meeting of researchers asked and answered about the previous material, students began to be able to connect the previous material with the material to be studied. In cycle II the researcher asked and answered about the material around the circle and the students were active and had understood the material beforehand.

\section{2) Core activities}

\section{Direct orientation phase}

Before students carry out activities to observe and observe the circle object that is studied directly on the activity instruction sheet, the researcher first directs students to form study groups and provides props and activity instructions to each group.In the first cycle of the first meeting, students were given activities to recognize and understand the elements of the circle. With their group friends, the students cut out a circle on the cardboard, then colored the circle and cut and pasted it on the prepared table. The results obtained in this phase are that students understand the concept of circular elements. In the second meeting, students were given activities to find the formula for the circumference of a circle by comparing the circumference of the circle and the diameter of the circle. The results of this activity students were able to find the concept of going around a circle. In cycle II students were given the activity of dividing the area of the circle into equal parts and arranging it into a rectangular shape to find the formula for the area of a circle. Through this activity the students succeeded in finding the concept of the area of a circle.

\section{Explanation phase}

After students carry out activities in direct orientation, then students state their views on the material being studied using the right language to explain the object being observed. Students discuss with their group friends to share their opinions on the material being discussed. The teacher's job is to help with language use. Furthermore, students communicate the results of group work in front of the class using their own sentences so that students are able to explain the material orally. In the first cycle of the first meeting, students were able to express their opinion about the elements of the circle. In the second meeting the students were able to explain in their own sentences about the circumference of the circle. In cycle II students are able to express their opinion about the formula for the area of a circle.

\section{Free Orientation Phase}

Students do individual assignments through LKPD that are distributed by the teacher. Worksheets contain questions related to the material being studied to improve students' understanding of the material and solve these questions in a way that is understood by students. In the first cycle of the first meeting, students worked on the circle elements of the exercises. The questions given relate to the circular elements. The results obtained, most of the students asked for teacher guidance to solve these problems. In the second meeting the students were given practice questions about the circumference of the circle. Most students are able to do assignments well. In cycle II students were given practice questions about the area of the circle and most students were able to do the practice questions well.

\section{3) Closing Activities}

\section{Integration Phase}

Researchers write new findings that support or deviate from the temporary agreement when students present the results of group work. The teacher guides students to make corrections and guides students to make conclusions. Students then summarize what they learned that day. The results obtained in the first cycle of meeting I, students still need teacher guidance to draw conclusions and summarize material about the elements of the circle. The second meeting, students have been able to draw conclusions even with teacher guidance. Cycle II, students were 
able to provide conclusions about the material that had been studied better with the guidance of the teacher.

At the end of the lesson, the researcher informed the students about the next meeting material. Furthermore, the researcher closed the lesson by reading prayers together and saying greetings.
The final action test cycle I was carried out after After the lesson, two meetings were held. The following is the work of one of the informants, namely AR.

Informant 3 (AR students with low abilities)

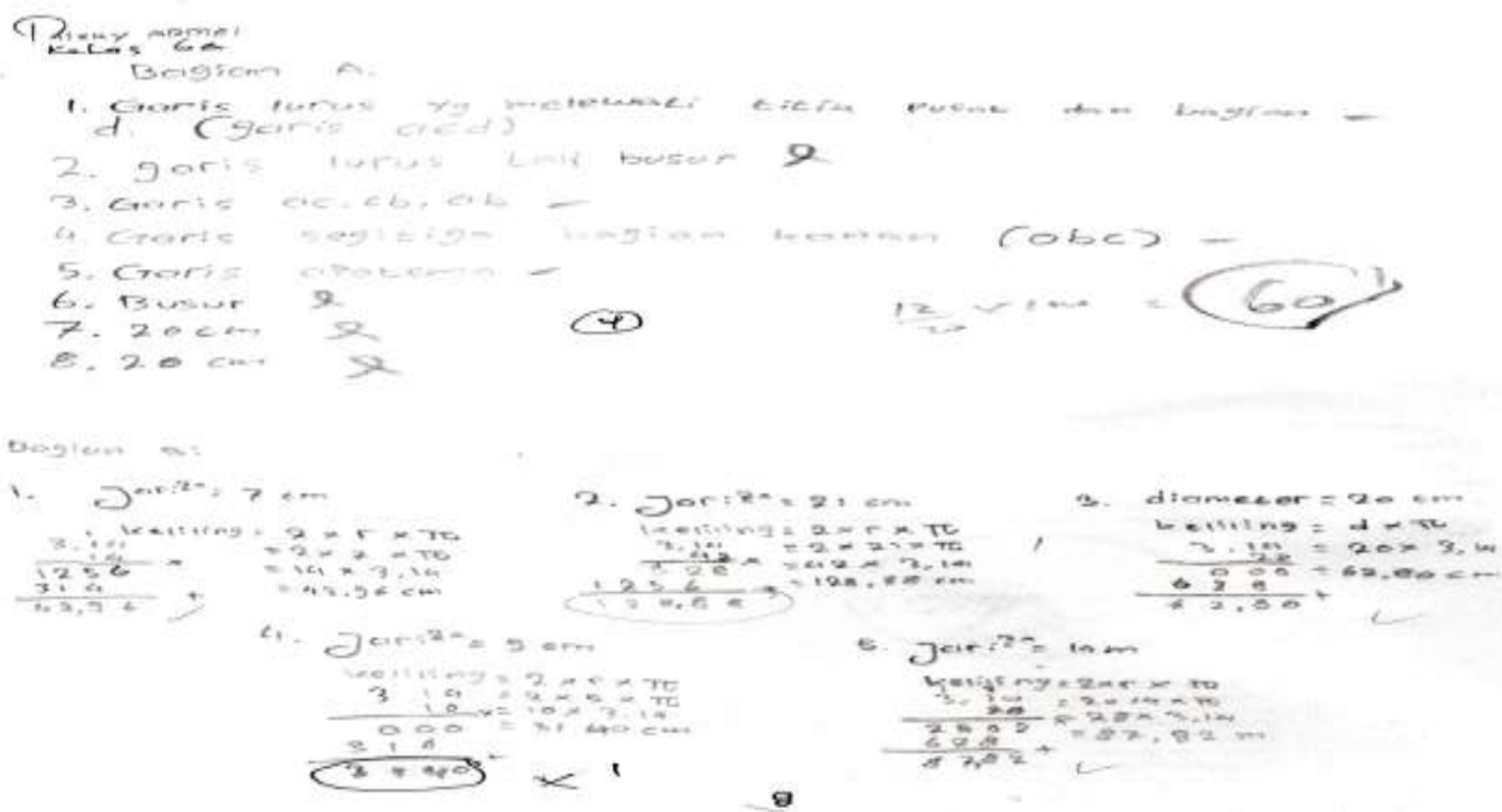

Figure 1. AR answers in the final test of Cycle I

From the results of the AR work above, it appears that $A R$ is still having trouble answering questions

about the definition of the elements of the circle and it is still not accurate to determine the final result of the answer about the circumference of the circle. The following is a snippet of an interview with AR.

AR S1 $15 \mathrm{P} \quad$ : Try to read the problem.

AR S1 $16 \mathrm{~S}$ : What three lines denote the radius?

AR S1 $17 \mathrm{P}$ : Well What are those fingers, remember?

AR S1 $18 \mathrm{~S}$ : Gosh, I forgot ma'am, even though I had read books before the test

AR S1 19 P : Then what other numbers are wrong?

AR S1 $20 \mathrm{~S}$ : I forgot everything mom

AR S1 $21 \mathrm{P}$ : So the radius is the line from the center to a point on the circle. The diameter is the diameter of the circle and the apothem is the shortest line between the center point and the chord.

AR S1 $22 \mathrm{~S}$ : Oh yes Mom, I understand.

AR S1 $23 \mathrm{P}$ : Then how about part two. Try to do it again. Looks like you got the wrong result.

AR S1 $24 \mathrm{~S}$ : Yes ma'am I did it again first
AR S1 25 P : KDon't forget where to put it, yes, write down the result.

AR S1 26 S : $171.88 \mathrm{bu}$

AR S1 $27 \mathrm{P}$ : Now that's the correct result. Next time you have to try more and be careful again

The results of the analysis of the final test action cycle I, obtained individual scores for the three informants, namely $\mathrm{FH}$ got a value of 100, AN got a value of 70 and AR got a value of 60 .

The analysis of the results of the final action test in cycle I is as follows:

Table 4.1 Student learning outcomes in cycle I

\begin{tabular}{|c|c|c|}
\hline Score & $\begin{array}{c}\text { The number of } \\
\text { students }\end{array}$ & Information \\
\hline$\geq 70$ & 12 & Completed \\
\hline$<70$ & 14 & Not complete \\
\hline total & 26 & \\
\hline
\end{tabular}

Based on the information on learning outcomes contained in the table, it is known that of the 26 students, there were 8 students who completed, namely those who obtained scores of more than or equal to 70 . While the remaining 18 people were 
students who scored below 70 or who were said to be incomplete. So that the percentage of classical completeness is obtained of $46.15 \%$. Based on the value of the percentage of classical completeness obtained, it shows that it has not reached the predetermined success criteria of action which is more than or equal to $75 \%$. In other words, the indicators of the success of the action in cycle I have not been achieved and need to be continued to cycle II.

The following are the results of the final test for the actions of one of the informants in cycle II, namely AR. In cycle II, the results of the analysis of the final action test in cycle II are as follows:

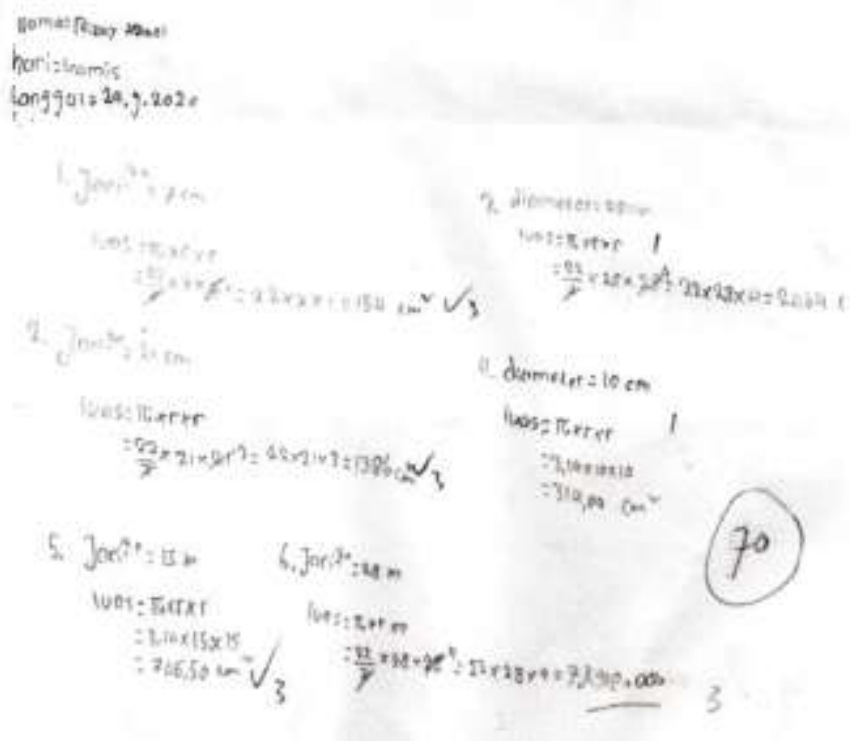

Figure 2. AR work on the final test of cycle II

Snippet of interview with AR students

AR S1 07 P : Now try to see the results of your test. It looks like there still some wrong answers. What number are still wrong

AR S1 $08 \mathrm{~S}$ : Number 3, 4 ma'am

AR S1 09 P : You know why it could be wrong

AR S1 $10 \mathrm{~S}$ : Yes ma'am, for not looking for it, his fingers. I don't change, I just wear diameter.

AR S1 11 P: $\quad$ What should I do

AR S1 $12 \mathrm{~S}$ : If 10 the radius is 5 , if the diameter is 28 the radius is 14 .

AR S1 $13 \mathrm{P} \quad$ : How is the breadth formula?

AR S1 $14 \mathrm{~S}$ : The formula is Phi times $r$ times $r$.

AR S1 $15 \mathrm{P}$ : Try to fix it again.

AR S1 $16 \mathrm{~S}$ : Yes ma'am, I'll count it first
AR S1 $17 \mathrm{P}$ : So if the radius is 14 , that means what is the formula

AR S1 $18 \mathrm{~S} \quad$ : Phi times 2 times $\mathrm{r}$ ma'a

AR S1 $19 \mathrm{P} \quad$ : You know ... phi times 2 times $\mathrm{r}$

AR S1 $20 \mathrm{~S} \quad$ : Ehh ... phi times $\mathrm{r}$ times $\mathrm{r}$ mom. 22/7 x 14 x 14

AR S1 $21 \mathrm{P} \quad$ : Yeah right ... so the result is $616 \mathrm{~cm}$ square.

AR S1 $22 \mathrm{~S}$ : Oh yes Mom, I understand.

The snippet of the conversation above shows that AR still does not understand the formula for the area of a circle if the question given uses a diameter.

The results of the final action test cycle II, obtained individual scores for the three informants, namely FH, AN and AR, respectively 100, 90 and 70 .

Based on the analysis of the final test results, data on student learning outcomes in cycle I were obtained as follows:

Table 4.2 Student learning outcomes in cycle II

\begin{tabular}{|c|c|c|}
\hline Score & $\begin{array}{c}\text { The number of } \\
\text { students }\end{array}$ & Information \\
\hline$\geq 70$ & 22 & Completed \\
\hline$<70$ & 4 & Not complete \\
\hline total & 26 & \\
\hline
\end{tabular}

Paying attention to the information on learning outcomes contained in the table above, it is known that there are 4 students who did not complete or who received scores below 70.Meanwhile, as many as 22 students can be said to be complete because their scores reached more than or equal to 70 . the percentage of classical completeness is $84.62 \%$. This percentage has reached the predetermined classical completeness criteria. In other words, the success of this action in cycle II has been achieved.

The aspects of teacher activity observed during learning using observation sheets are: (1) opening with an opening greeting and praying to start learning, (2) checking student attendance and preparing physically and psychologically for learning, (3) providing an overview of the benefits of the material being studied, (4) convey the learning objectives at the ongoing meeting, (5) explain the learning implementation mechanism, (6) the teacher asks several questions about the material to be studied (7) directs students to form study groups and provides props and activity instructions for each group,(8) facilitating students to examine the subject matter through teaching materials (tools) designed by the teacher (9) facilitating each group to make presentations and giving other groups the opportunity to ask questions or respond, (10) give praise to the group that has done presentations or express their opinions, (11) provide practice questions to be done individually, (12) observe and provide sufficient guidance if needed, (13) direct students to make a summary / conclusion of the lesson about important points in 
new learning activities, ( 14) planning follow-up activities and delivering lesson plans at the next meeting, (15) praying and closing the lesson and finally managing time, using learning resources and utilizing mediause of learning resources and use of mediause of learning resources and use of media

The results of observations of research activities in the first cycle of the first meeting showed that aspects number 4 and 15 were categorized very well. Aspects number 2, 7, 8, 12 and 13 are categorized as good .. Aspects 1, 3, 5, 6, 9,10, 11, 14 and 16 are in the poor category. The results of observations of research activities in the first cycle of the second meeting showed an increase. Aspects that were previously good at the first meeting had increased at the second meeting, namely showing very good categories, namely aspects $2,4,8,12,14,15$. Aspects number $1,5,6,7,11,13$, and 16 were categorized as good . Aspects number 3, 9, and 10 are still in the poor category. The results of observations of the researcher's activity in cycle II showed that aspects number $1,2,4,5,6,8,11,12,14,15$ and 16 were categorized as very good. Aspects $3,7,9,10$, and 13 are categorized as good.From the results of observations in cycle II, it can be seen that all activities carried out by the teacher are in the good and very good categories, which means that there has been an increase from cycle I to cycle II.

The aspect of student activity that are observed during learning take place using observation sheets are (1) saying the opening greetings and praying (2), listening to the teacher check attendance and preparing to start learning (3) listening to the benefits of learning lesson (4) listening to the objectives ongoing learning (5)listening to the implementation mechanism of the learning process according to the learning steps (6) listening to the teacher's explanation and answering question about the material to be studied (7) sitting in groups and receiving props and activity instructions (8) working on instructions activities and ask for teacher guidance when experiencing (9) make presentations and ask question or respond to other groups (10) get praise if they have made presentations or express their opinions (11) receiving LKPD to be worked on individually, (12) asking for sufficient guidance when experiencing difficulties, (13) making lesson summaries / conclusions, (14) listening to lesson plans for the next meeting, (15) praying and saying greetings to end the lesson, and finally time management, use of learning resources and media utilization. The assessment of each aspect is carried out by giving a score, namely a score of 4 means very good, a score of 3 means good, a score of 2 means less, and a score of 1 means very poor. use of learning resources and use of media. The assessment of each aspect is carried out by giving a score, namely a score of 4 means very good, a score of 3 means good, a score of 2 means less, and a score of 1 means very poor. Use of learning resources and use of media. The assessment of each aspect is carried out by giving a score, namely a score of 4 means very good, a score of 3 means good, a score of 2 means less, and a score of 1 means very poor.
The results of observations of student activities in the first cycle of the first meeting, aspects number 3, 4, and 15 were categorized as very good. Aspects 2, 5, 12, 13, and 14 are categorized as good. Aspects number 1, 6, 7, 8, 9, 10, 11 and 16 are categorized as less. The results of observations of student activities in the first cycle of the second meeting, student activity had increased in several aspects, namely aspects number 2, 3, 4, 12 and 15 were categorized as very good. Aspects number 1, 5, 6, 9, 10, 11, 13, and 14 are categorized as good. While the aspect that still shows the lack of category at this meeting is aspect number 7. Aspect (7) describes the students when sitting with their groups are still less orderly. From the results of observations of student activities at the first and second meetings there are still many aspects that must be improved so that they become better and very good in the next cycle. Data from the observation of student activity in cycle II are as follows: aspects number 1, 2, $3,4,5,6,9,10,11,12,14$ and 16 are categorized as very good. Aspects number 7, 8, 10, and 13 are categorized as good. The results of observations in cycle II have shown an increase.

\section{DISCUSSION}

The research conducted is a Classroom Action Research (CAR) which aims to improve student learning outcomes in circle material in class VI A SD Inpres Palupi, Tatanga District, Palu City. The research was conducted from 25 August 2020 to 26 September 2020.

This research was conducted in two cycles. Each cycle consists of 4 components, namely: (1) planning, (2) action, (3) observation, and (4) reflection, as developed by Arikunto, S. In the implementation of the action the researcher applied the Van Hiele learning model assisted by manipulative media, so that students could express their thoughts, exchange opinions, cooperate with each other if there were friends in the group who had difficulties. This is in accordance with the opinion of Magrib (2018) that Van Hiele learning which consists of five learning phases can guide students in constructing geometric concepts. These phases are the information phase, orientation phase, explanation phase, free orientation phase and integration phase. In the information phase a teacher ensures students' ability to geometric shapes, Furthermore, in the orientation phase of abstract geometric shapes, the learning media will be concrete. Students manipulate the learning media so that a concept is created and the teacher ensures its correctness in the explanation phase. Furthermore, doing exercises to prove understanding of concepts in the free orientation phase and in the end students are able to draw conclusions about the material in the integration phase (Husnul, 2013). This research begins with pre-research activities. In pre-research activities, the researcher identifies the problems in class VI that the researcher is teaching. Then the researcher determined the research subject, namely the students of class VI A. After that the researcher gave the initial test to all the students who were the research subjects to find out the students' abilities on the prerequisite material and as a guide in determining informants and in group 
formation. This is in line with the opinion of Sutrisno (2012), which states that the implementation of the test before treatment is carried out to determine students' initial understanding. The results of the student's initial test analysis were used as a guide in determining informants. Informants are selected with different qualifications, namely high, medium and low abilities.

In the implementation of learning cycle I and cycle II, each researcher meeting follows learning steps consisting of preliminary activities, core activities and closing activities with Van Hiele learning phases namely phase (1) Information, phase (2) Direct orientation, phase (3) explanation, phase (4) Free Orientation, and phase (5) of integration. The description of the implementation of learning activities in cycle I and cycle II using the Van Hiele learning phases assisted by manipulative media as follows:

\section{1) Preliminary activities}

The activity begins with open learning activities, namely; the researcher opens the lesson by saying greetings, inviting students to pray, checking student attendance and preparing students to learn. This activity aims to attract students' attention at the beginning of learning. In the first cycle, the results showed that in this activity students could answer greetings well and pray but were less orderly. In the second cycle, the results showed that this activity students could answer greetings politely and pray in an orderly manner. So it can be concluded that the results obtained were the students answered greetings politely and prayed orderly. Then the researcher checked the attendance of the students and prepared the students. In the first cycle, the results show that the teacher can find out which students are not present on that day and students can prepare themselves to attend the lesson but the atmosphere is not orderly. In the second cycle, the results showed that the teacher could know the presence of all students in the learning process that day and students could prepare themselves to take part in learning well. So it can be concluded that the results obtained are that the teacher can identify students who are not present at that time and students can prepare themselves to take part in the learning process. This is in line with the opinion of Amrullah (2014) which states that teacher activities open learning by saying greetings, inviting students to pray together, checking student attendance and preparing students to learn can attract students' attention at the beginning of learning. So it can be concluded that the results obtained are that the teacher can identify students who are not present at that time and students can prepare themselves to take part in the learning process.

Furthermore, the researcher provides an overview of the benefits of the lesson at that time.After students know the benefits, students become motivated to take part in learning activities. In the first cycle, it was found that students could find out the benefits of studying circles and in the second cycle, the results showed that students could find out the benefits of studying the area of a circle so that it could be concluded that students could find out the benefits of the material to be studied so that the lesson was more meaningful. This is in accordance with the opinion of Wijayanti (2010) that one of the ways teachers can generate student learning motivation is to convey the benefits of the material being studied.

The next activity the researcher conveyed the learning objectives to be achieved in learning. In the first cycle, the results obtained, students can know the learning objectives to be achieved. In the second cycle, the results showed that students could know the learning objectives to be achieved so that students were more focused in the learning process. So it can be concluded that students can know the learning objectives to be achieved and students are more focused in the learning process. This is in line with the opinion of Sanjaya (2009) that explaining learning objectives to students is necessary so that students are more focused in learning.

The next activity the researcher explains the learning implementation mechanism according to the learning steps. The results obtained in cycles I and II students know the series of activities to be carried out in the ongoing learning.

\section{Information phase}

The researcher's activity of giving apperception by asking students a few questions about material related to circles to find out and attract students' attention was the first phase in Van Hiele's learning. Thus students can recall and understand the prerequisite material before studying the circle material. In the first cycle, it was found that in this activity students were still not actively answering the questions raised by the researcher. In the second cycle, it was found that there were many students who actively answered the questions asked by the researcher. This is in accordance with the opinion of Hudojo (1990) which states that before studying concept B, one needs to first understand the concept $\mathrm{A}$ which underlies concept $\mathrm{B}$. Because without understanding concept $\mathrm{A}$, it is impossible for that person to understand concept B. So it can be concluded that students initially lacking active after passing one learning cycle to be more active.

\section{2) Core activities}

\section{Live Orientation Phase}

In this phase, the researcher's activity is to direct students to form groups, distribute props and activity instructions and facilitate students to research material through teaching materials and teaching aids designed by researchers.This group division aims to train students to work together and students can exchange ideas. In cycle I, it was found that the students understood the concept of circle elements. In the second meeting, students were given activities to find the formula for the circumference of a circle by comparing the circumference of the circle and the diameter of the circle. The results of this activity students were able to find the concept of going around a circle. In cycle II students were able to find the formula for the area of a circle. Through this activity the students succeeded in finding the concept of the area of a circle. This is in line with the 
opinion of Mukhlesi (2011) that using media can improve understanding of the concept of geometry.

\section{Explanation phase.}

The researcher facilitates each group to make a presentation and other groups ask or respond and give praise to students who have finished their presentation or submit their opinions. In cycle I, the results show that some students are able to present the results of group work even though there are still students who do not dare to present the work of the group. In the second cycle, it was found that many students asked to present the results of their group work so that it was appreciatedtheir courage, all group members are welcome to come forward and take turns presenting the results. However, there are still drawbacks, namely only a small number of people dare to respond to the answers of other groups.

\section{Free Orientation Phase}

In this phase, students work on individual assignments through the LKPD distributed by the teacher. LKPD contains questions related to calculating the area of a circle to increase students' understanding of the material that has been studied. The results obtained in cycles I and II students were orderly in doing the exercises given by the researcher and did not hesitate to ask for guidance from researchers if they did not understand how.

\section{3) Closing Activities}

\section{Integration Phase}

In this phase the researcher directs students to make conclusions about the lessons that have been learned. In cycles I and II, most students were able to provide conclusions about the material that had been studied even though they still needed guidance from the teacher. This is in line with the opinion of Purnomo (2011) that teachers guide students to draw conclusions with student findings. The closing activity concludes with planning follow-up activities and praying and closing the lesson by saying a greeting. The results obtained in cycles I and II were students who were orderly and calmly listening to the follow-up activities delivered by the teacher and praying fervently.

After checking the results of the final action test cycle I, of the 26 students who took the final test, there were 12 students who completed and 14 students who did not. So that classical completeness in the first cycle is $46.15 \%$. Whereas in the second cycle the results obtained were 22 students who completed and 4 students who did not complete, so that classical completeness in the second cycle was $84.62 \%$. This increase occurred because students were already active in learning in cycle II so that when they were given the final test, many of them already understood the material that had been studied.

Based on the results of interviews related to the material of the elements of the circle, the circumference of the circle and the area of the circle, it was found that the student was still wrong about the elements of the circle due to forgetting and confusion. In the part of calculating the circumference, information was obtained that the students had understood the formula for the circumference of a circle and understood how to solve the circumference of the circle but were not careful in calculating. Other information obtained is that students like to study in groups with the Van Hiele learning model because they can solve problems together. In the second cycle the results of the interviews showed that students still enjoyed learning with the Van Hiele learning model and working in groups.

Based on data from observations of teacher (researcher) activities, in the first cycle data was obtained that the researcher was less clear in providing an explanation of the benefits of lessons, the mechanism of activities, asking prerequisite material questions, guiding during group work and giving less praise to students. In the second cycle, the results obtained by the researchers were good in providing benefits about the material, both in explaining the mechanism of activities, and having guided students and giving praise well.

Based on the data from observations of student activity, it was obtained that the student data were still not orderly at the start of lessons, were not active in answering questions posed by researchers, sitting in groups was not orderly, not all students had the courage to present the results of their group work and still needed guidance in making conclusions. In cycle II students were more orderly and active in group work and many students were willing to present their group work and conclude lessons.

Based on cycle I field notes, several notes were: when learning was about to begin, there were still many students who were not orderly, there were some students who wanted to move groups because they wanted to study with friends in other groups who were familiar with them so that the class became a bit rowdy, when they were going to work on instructions There are still many students who tell stories with their group friends who do not understand the activities to be carried out, and the teacher has not provided maximum reinforcement at the time of presentation and concludes the material and in giving praise.as long as the learning process in cycle ii takes place, namely when learning is more orderly, students look more serious and active in working on activity instructions. This can be seen from the number of students who ask the researcher to confirm whether their work is correct or not and to ask for guidance in completing activity instructions so that students are able to complete the activity instructions within a predetermined time and students who are named to present the results of their group discussions dared to appear in front of the class to present the results of the group discussion.

Based on the results and discussion described above, it was obtained data that the application of the Van Hiele learning model assisted by manipulative media could improve student learning outcomes on circle material in class VI A SD Inpres Palupi. This is indicated by the increase in the results of observations of teacher and student activities who are in the poor and good categories to become good and very good in cycle II. While the results of the final action test indicated by the classical 
completeness achieved in cycle $\mathrm{I} 46.15 \%$ increased to $84.62 \%$ in cycle II.

\section{CONCLUSION}

Based on the description of the results of the research and discussion, it can be concluded that the application of the Van Hiele learning model assisted by manipulative media on circle material can improve the learning outcomes of grade VI students at SD Inpres Palupi by following the following phases: phase (1) information, phase (2) ) direct orientation, phase (3) explanation, phase (4) free orientation and phase (5) integration. In the information phase, the researcher conducts questions and answers related to circular material. In the direct orientation phase, the researcher directs students to form study groups and provides props and activity instructions to each group. In the explanation phase, the researcher asks group representatives who will advance to present the results of their group work.In the free orientation phase, the researcher provides practice questions for students to work on individually and observes and provides adequate guidance if needed by students. The last phase is integration, the researcher directs students to make conclusions about the material they have learned that day. The results show that the application of the Van Hiele learning model assisted by manipulative media can improve student learning outcomes on circle material in class VI A SD Inpres Palupi. This is indicated by the increase in the results of observations of teacher and student activities in cycle I which are in the poor and good category to be good and very good in cycle II. While the results of the final action test indicated by the classical completeness achieved in cycle $46.15 \%$ increased to $84.62 \%$ in cycle II.

\section{SUGGESTION}

Some suggestions that researchers can convey based on the research results obtained are as follows:

1. Van Hiele's learning model assisted by manipulative media can be considered as an alternative for mathematics teachers as an alternative in choosing a learning model that can support the efforts to improve students' understanding of geometry material.

2. Prospective researchers who also want to apply the Van Hiele learning model, might try other geometric materials.

\section{REFERENCES}

[1] Abdullah, A., Surif, J., Ibrahim, NH, \& Zakaria, E. (2015). Enhancing students' geometrical thinking levels through Van Hiele's phase-based Geometer's Sketchpad-aided learning. IEEE 7th International Conference On Engineering Education (ICEED), 105-111. https://doi.org/: 10.1109 / ICEED.2015.7451502

[2] Abdussakir, A. (2012). Learning Geometry According to Van Hiele's Theory. Madrasah, 2 (1). https://doi.org/10.18860/jt.v2i1.1832.

[3] Amrullah, AL (2014). Application of the Realistic Mathematics Education Approach to Improve Student Learning Outcomes on Question Questions About Assemblies in Class VII MTs Negeri Palu Barat. Tadulako Mathematics Education Electronic Journal. [On line]. Vol. 2, No. 1. Pages: 4-8. Available: http://jurnal.untad.ac.id/jurnal/index.php/ JEPMT / Article / download / 3226/2281

[4] Arikunto, S., Suhardjono, \& Supardi. (2017). Classroom Action Research (Revised Edition; Suryani, Ed.). Jakarta: PT Bumi Aksara.

[5] Ministry of Education and Culture. (2016). Copy of Appendix to Regulation of the Minister of Education and Culture Number 21 of 2016 of 2016 Concerning Content Standards for Primary and Secondary Education. 1-234.

[6] Ministry of National Education. (2006). Education unit level curriculum (KTSP) 2006 for mathematics subjects. Ministry of Education.

[7] Hudoyo, Herman (1990) Mathematics Teaching and Learning Strategies. Malang: IKIP Malang.

[8] Husnul, K. (2013). Improve geometry learning outcomes with van hiele theory. Strengthening the Role of Mathematics and Better Mathematics Education, (November), 978-979.

[9] Isjoni. (2010). Cooperative Learning Effectiveness of Group Learning. Pekanbaru: Alfabeta.

[10] Junedi. (2017). Application of Van Hiele's Learning Theory to Geometry Materials in Class Viii. Journal of Mathematics Education and Science), ISSN (1), 2528-4363.

[11] Maghrib. (2018). Application of Van Hiele Learning Theory to Quadrilateral Material to Increase Activities and Learning Achievement of Class VII Junior High School Students Paradigm change, namely from conventional learning to students and can provide good competency provisions for mom studies. Journal of Mathematics Education Thought and Research, 1 (2), 68-79.

[12] Miles, MB, \& Huberman, AM (1992). Qualitative Data Analysis (Matter I). Jakarta: University of Indonesia Publishers (UI-Press).

[13] Mukhlesi, E. (2011). Utilization of Manipulative Objects to Improve Understanding of Geometry Concepts and Observation Ability of Class V Elementary School Students. (1), 63-75.

[14] Muzdalivah, Tandiayuk, MB, \& Anggraini. (2016). Application of the Van Hiele Learning Model for Surfaces and Volume of Cubes and Blocks in Class VIII of SMP Negeri 18 Palu. Journal of Mathematics Education, 5 (3), 231-243.

[15] Sanjaya, Vienna. (2009). Planning and Design of Learning Systems. Jakarta: Golden.

[16] Sutrisno. (2012). Learning Effectiveness with Guided Discovery Methods on Students' Understanding of Mathematical Concepts. Journal of Mathematics Education [Online]. Vol. 1 (4), 16 pages.

[17] Turella, R., \& Dyiah, LA (2016). Assessment of Learning Process and Outcomes in Primary Schools. Jakarta: Directorate General of Teachers and Education, Ministry of Education and Culture. 